\title{
Transcatheter aortic valve implantation combined with other heart interventions: current status and future perspectives
}

\author{
Ana Paula Tagliari, ${ }^{1,2}$, Maurizio Taramasso ${ }^{1}$ \\ ${ }^{1}$ Cardiac Surgery Department, University Hospital of Zurich, University of Zurich, Zurich 8091, Switzerland. \\ ${ }^{2}$ Postgraduate Program in Health Sciences, Cardiology and Cardiovascular Sciences, Universidade Federal do Rio Grande do Sul, \\ Porto Alegre 2400, Brazil.
}

Correspondence to: Dr. Ana Paula Tagliari, Cardiovascular Surgery Department, University Hospital of Zurich, Rämistrasse 100, Zurich 8091, Switzerland. E-mail: anapaula.tagliari@usz.ch

How to cite this article: Tagliari AP, Taramasso M. Transcatheter aortic valve implantation combined with other heart
interventions: current status and future perspectives. Vessel P/us 2020;4:16. http://dx.doi.org/10.20517/2574-1209.2020.05

Received: 19 Jan 2020 First Decision: 16 Mar 2020 Revised: 18 Mar 2020 Accepted: 20 Mar 2020 Published: 16 Jun 2020

Science Editor: Mario F. L. Gaudino Copy Editor: Jing-Wen Zhang Production Editor: Jing Yu

\begin{abstract}
Transcatheter aortic valve implantation is a well-proven effective treatment option for patients with severe symptomatic aortic valve stenosis requiring valve replacement in all risk classes. Frequently, however, other concomitant cardiovascular conditions demanding intervention are present, and a combined approach is required. Here, we discuss some of the most frequent combined settings. The decision about which approach (staged or simultaneous) is more suitable for each patient needs to be based on individual characteristics and clinical, anatomical, and procedure-related factors.
\end{abstract}

Keywords: Transcatheter aortic valve implantation, combined procedure, heart valve disease, percutaneous coronary intervention, outcomes

\section{INTRODUCTION}

In the last years, transcatheter aortic valve implantation (TAVI) has become a well-proven effective treatment option for patients with severe symptomatic aortic valve stenosis (AS) requiring valve replacement at high or intermediate surgical risk. Nowadays, with the expansion of TAVI for low-risk populations, the number of individuals undergoing TAVI will increase even more. Frequently, however,

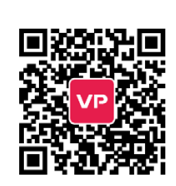


patients with AS have other concomitant cardiovascular conditions demanding a combined approach. In this scenario, the ability to perform TAVI combined with other transcatheter heart interventions becomes crucial.

Here, we discuss some of the most frequent settings that have been considered for combined intervention with TAVI, either concomitantly or staged.

\section{PERCUTANEOUS CORONARY INTERVENTION}

As the majority of patients with AS scheduled for TAVI are older than 75 years ${ }^{[1-3]}$, it is not a surprise that up to $50 \%$ of preoperative cardiac catheterizations reveal coexisting coronary artery disease $(C A D)^{[4]}$. In high- and intermediate-risk TAVI trials, for instance, concomitant CAD was present in about two-thirds of patients ${ }^{[2,5-7]}$, and even in the low-risk cohorts, concomitant coronary revascularization was indicated in about $7 \%^{[8,9]}$.

According to current European guidelines, percutaneous coronary intervention (PCI) should be considered in patients with primary indication to undergo TAVI presenting with coronary artery diameter stenosis $>70 \%$ in proximal segments (Class IIa, Level C) ${ }^{[10]}$. It has not been addressed, however, as to when PCI should be performed.

Simultaneous procedures have the advantage of decreasing repeated puncture or incision of vessels, reducing patients' suffering and length of hospital stay, and saving medical resources ${ }^{[11]}$. However, radiation exposure and the amount of contrast used are usually higher ${ }^{[12]}$.

PCI before TAVI, on the other hand, has the potential to minimize ischemic risk during TAVI, particularly during rapid ventricular pacing, and to overcome difficulties associated with coronary access post-TAVI. Conversely, the patient remains at risk for valvular decompensation and needs to be put on dual antiplatelet therapy, which may increase the risk of bleeding during TAVI ${ }^{[1-13]}$.

PCI after TAVI is relatively rare because prosthetic valve commissures, or stent frame, may be positioned close to coronary ostia, interfering with coronary diagnostic or guiding catheters ${ }^{[14]}$. Trying to facilitate future coronary reaccess, Tang et al. ${ }^{[15]}$ have suggested some landmarks to predict coronary overlap severity based on initial TAVI deployment orientation. These findings have significant implications as TAVI moves to younger and low-risk patients, where valve durability and CAD progression are notable concerns. Neocommissure alignment thus becomes a new trend to be pursued during TAVI intervention.

Regarding scientific evidence supporting simultaneous or staged procedures, a systematic review of 4 studies, comprising 209 patients, showed no difference in 30-day mortality ( $\mathrm{OR}=1.47,95 \% \mathrm{CI}$ : 0.47-4.62), renal failure $(\mathrm{OR}=3.22,95 \% \mathrm{CI}$ : 0.61-17.12), periprocedural myocardial infarction $(\mathrm{OR}=1.44,95 \% \mathrm{CI}: 0.12$ 16.94), life-threatening bleeding $(\mathrm{OR}=0.45,95 \% \mathrm{CI}: 0.11-1.87)$, and major stroke (OR $=3.41$; 95\%CI: 0.16 74.2) when PCI was performed concomitant or staged with TAVI ${ }^{[1]]}$.

Similarly, a recent paper demonstrated no significant difference in life-threatening or major bleeding, and acute kidney injury among patients who underwent planned pre-TAVI $(n=156)$, post-TAVI $(n=40)$, or concomitant $(n=77)$ PCI. Cumulative 2-year mortality was also similar across the groups $(29.7 \% v s .14 .8 \%$ vs. $10.3 \%$ in pre-TAVI, concomitant, and post-TAVI, respectively; $P=0.11)^{[16]}$.

In current practice, PCI has been carried out at the time of TAVI in the presence of significant coronary lesions provided that procedural risk does not outweigh the potential benefit [Figure 1]. The final decision 

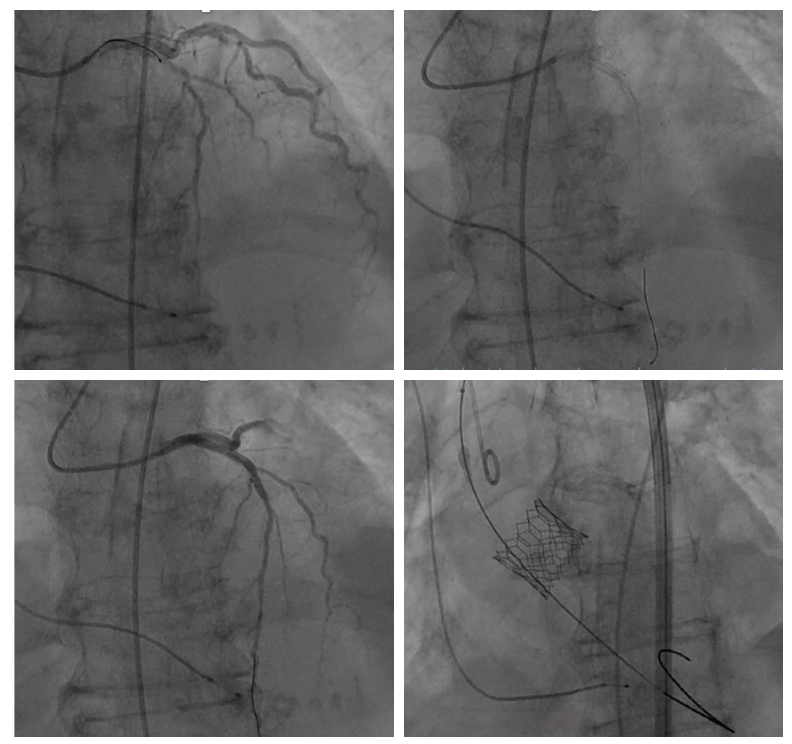

Figure 1. Transcatheter aortic valve implantation simultaneous to percutaneous coronary intervention in an 81-year-old female patient with severe symptomatic aortic stenosis and severe proximal left anterior descending coronary artery stenosis. In this patient, percutaneous coronary intervention using 2 drug-eluting stents was performed first, followed by transfemoral implantation of a 26-mm balloon-expandable Edwards SAPIEN 3 valve

should take into account patient clinical conditions, CAD burden, and the amount of myocardium at risk $^{[10]}$. Penkalla et al. ${ }^{[12]}$ suggested some additional anatomical criteria, as follows: (1) left main coronary artery stenosis > 50\%; (2) coronary stenosis of $90 \%$ or more in the proximal or mid-left anterior descending coronary artery; or (3) coronary stenosis of $90 \%$ or more in the proximal or mid-right coronary artery (if dominant artery); or (4) coronary stenosis of $90 \%$ or more in the proximal or mid-left circumflex artery (if dominant).

\section{MITRAL VALVE INTERVENTIONS}

Moderate or severe mitral regurgitation (MR) is present in $22 \%$ to $48 \%$ of patients with severe AS undergoing TAVI ${ }^{[17-20]}$, particularly in those inoperable or at high-risk ${ }^{[1,2]}$. These individuals constitute a particular subgroup that could benefit from combined transcatheter interventions.

Although few studies have suggested that MR is not an independent predictor of mortality after TAVI ${ }^{[20,21]}$, the majority of authors point out a significant increase in mortality risk if moderate to severe MR is present at the time of TAVI ${ }^{[22-24]}$.

Among the factors that should tailor indication of combining TAVI with an MR intervention are the following: individual patient's characteristics such as age, comorbidities, life expectancy, and frailty; valve characteristics such as MR severity and etiology; together with some technical aspects and procedural risks $^{[10,25]}$.

MR etiology is a particularly important issue since a less aggressive management could be indicated in the setting of functional MR, assuming that some improvement in MR severity is expected to occur after $\operatorname{TAVI}^{[2,2,2]}$. Thus, a staged approach may be reasonable, with the aortic valve being addressed first, and the mitral valve treated only in those who remain symptomatic in spite of a successful TAVI. On the contrary, in the setting of a predominantly primary MR, as structural valve alterations are not expected to improve, bivalvular interventions should be advocated ${ }^{[25,28]}$. 

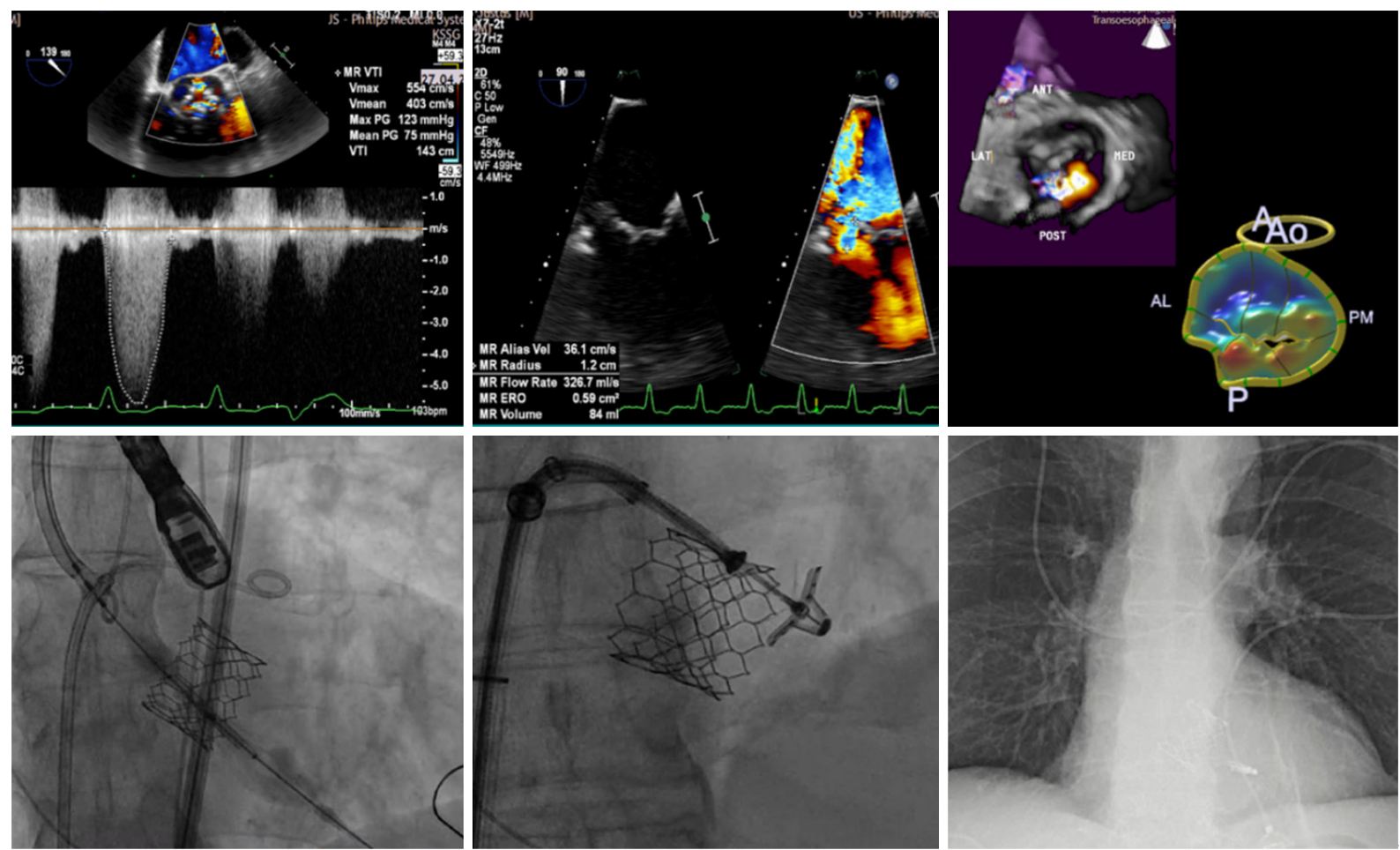

Figure 2. Transcatheter aortic valve implantation concomitant with percutaneous edge-to-edge mitral valve repair in a 70-year-old male patient with severe symptomatic aortic stenosis and severe degenerative mitral regurgitation due to posterior leaflet prolapse (the first 3 images). The procedure was started by the transseptal puncture, followed by transfemoral implantation of a 29-mm balloon-expandable Edwards SAPIEN 3 valve. The last step was MitraClip implantation under transesophageal echocardiogram and angiographic control

If a double-valve transcatheter replacement is indicated since the majority of the mitral devices are delivered transapically, a simultaneous approach through the same access can be used ${ }^{[29]}$. Regarding the best order, usually the aortic valve is performed first. The rationale for this strategy is that, since the aortic and mitral annuli are contiguous, bridged by the aorto-mitral fibrous curtain ${ }^{[30]}$, some degree of obstruction for the new aortic valve deployment can happen if the mitral is treated first ${ }^{[29]}$. This same order has been adopted during transapical TAVI simultaneous with NeoChord implant ${ }^{[31]}$.

In the case of TAVI combined with percutaneous edge-to-edge mitral valve repair, a common strategy is to start with the transseptal puncture under partial anticoagulation, followed by TAVI delivery under full anticoagulation, finalizing with the percutaneous mitral valve repair [Figure 2]. To minimize the time with a large device in the iliofemoral system, the arterial sheath can be removed before starting the mitral valve procedure $^{[25]}$.

Last but not least, some reports have also supported TAVI combined with valve-in MAC (mitral annular calcification), either by transfemoral/transseptal or transapical access ${ }^{[32,33]}$.

Summarizing current data, a systematic review of combined aortic [TAVI or transcatheter aortic valvein-valve (TAViV)] and mitral valve interventions [transcatheter mitral valve replacement (TMVR), transcatheter mitral valve-in-valve/valve-in-ring (TMViV/ViR), or percutaneous mitral valve repair (PMVR)], involving 60 patients from 37 studies, showed that the main reason for combined approach was severe AS (92\%) associated with moderate/severe MR (65\%). In the majority of the cases, the aortic valve intervention was performed before the mitral valve. Mortality rates were $25 \%$ for TAVI plus TMVR, $17 \%$ for 
TAVI plus TMViV/ViR, 0\% for TAViV plus TMViV/ViR, and 15\% for TAVI/ViV plus PMVR. Significant post-procedure paravalvular leak was rare in all combinations ${ }^{[29]}$.

It is also important to remember some caveats regarding MR evaluation in the presence of AS. MR jet velocity can be increased due to high left ventricular pressures ${ }^{[34]}$, while AS transvalvular gradient and flow can be hampered by the presence of $\mathrm{MR}^{[35]}$.

\section{TRICUSPID VALVE INTERVENTIONS}

Significant tricuspid regurgitation (TR) is diagnosed in about $10 \%$ of patients with severe AS, and usually indicates right ventricular dysfunction ${ }^{[36,37]}$.

Although severe TR has been associated with high mortality in patients with concomitant severe AS conservatively treated, some authors have suggested that moderate or severe TR can improve after TAVI $^{[17,38]}$. Contradicting this idea, others have argued that TR will persist and that it is independently associated with increased mortality following TAVI ${ }^{[17,39,40]}$.

To clarify the true impact of TR in patients with severe AS undergoing TAVI, a recent meta-analysis evaluated 12 studies enrolling 41,485 TAVIs. Early and mid-term mortality were 1.80- and 1.96-fold increased, respectively, in the presence of significant TR $(\mathrm{OR}=1.80,95 \% \mathrm{CI}: 1.01-3.19$; $\mathrm{OR}=1.96,95 \% \mathrm{CI}$ : $1.35-2.85)^{[40]}$. These findings were similar to those reported by Pavasini et al ${ }^{[41]}$, whose study demonstrated a 2.0-fold increase in all-cause mortality if moderate to severe TR was present after TAVI (95\%CI: 1.52-2.91). The authors' conclusion was that a more detailed and shared TR severity evaluation would be necessary to understand its impact and the need for a combined approach in patients undergoing TAVI.

Opposing the above-mentioned statements, Barbanti et al. ${ }^{[42]}$ showed that, in patients with moderate to severe TR submitted to TAVI, all-cause mortality risk was higher only in the presence of left ventricular ejection fraction $>40 \%$, suggesting that in patients with severely depressed ejection fraction, severe TR is rather a surrogate marker of advanced disease than a real cause of worse outcomes.

Regarding the feasibility of combined approaches, in 2017, Reichart et al. ${ }^{[43]}$ described a successful case of concomitant TAViV and tricuspid valve-in-ring using a 23-mm self-expanding transcatheter bioprosthesis in aortic position and a $29-\mathrm{mm}$ balloon-expandable transcatheter bioprosthesis in tricuspid position. The authors highlighted that, for the rapid ventricular pacing maneuver, external pacemaker patches were used to avoid the lead crossing through the tricuspid valve. Another option could be the use of a temporary lead inserted through the coronary sinus ${ }^{[44]}$ or pacing over the left ventricular guidewire ${ }^{[45]}$.

Another appealing case was reported by Abdi et al. ${ }^{[46]}$, who combined TAVI with tricuspid valve-in-valve in a patient with rheumatic heart disease. The balloon-expandable valve implanted in tricuspid position was oversized by about $20 \%$ relative to the internal diameter of the previous bioprosthesis. The authors stressed, however, that an excessive oversizing may impair leaflet opening, leading to early valve degeneration.

Considering the above evidence, it is clear that the tricuspid valve is a relatively non-explored territory, but a potential target for combined transcatheter approaches.

\section{AORTA INTERVENTIONS}

Abdominal aortic aneurysm occurs in around 6\% of patients undergoing TAVI, a number that is increasing due to population aging, especially because both conditions share similar risk factors ${ }^{[47]}$. 
Despite no clear recommendation available, the idea of combining TAVI with abdominal endovascular aneurysm repair (EVAR) seems appealing. Some potential benefits of simultaneous approaches are as follows: to prevent a potential aortic rupture related to the abrupt rise in blood pressure after relieving aortic valve gradient; to reduce vascular complications by accessing the artery a single time; and to shorten length of hospital stay by combining the two strategies in a single procedure ${ }^{[48,49]}$.

Regarding which specific procedure should be done first, Sato et al. ${ }^{[49]}$ and Mauri et al. ${ }^{[50]}$ prefer to perform TAVI before EVAR, while Natour et al. ${ }^{[51]}$ advocate starting with EVAR and then to use the same sheaths and wires for the subsequent TAVI.

Performing EVAR first has the advantage of reducing the risk of vascular dissection caused by crossing the aorta with the valve delivery system and preventing aneurysmal sac lesion due to sudden blood pressure rise following TAVI. Furthermore, the increased clot burden within the aneurysmal sac and the consequent risk of distal embolization may be an additional reason to prefer doing EVAR first. On the other hand, performing TAVI first would avoid the risk of crossing the aortoiliac prosthesis, as well as reducing the risk of local thrombosis due to a large EVAR sheath prolonged time within peripheral vessels ${ }^{[50]}$.

Another emerging possibility is combining TAVI with thoracic endovascular aortic repair (TEVAR). In 2014, Komlo et al. ${ }^{[52]}$ reported the first case of a single-stage TAVI and TEVAR in a patient with critical AS and descending thoracic aorta aneurysm. In this case, direct transaortic access via minimally invasive partial sternotomy was chosen.

Furthermore, a relatively new concept is to treat the aortic valve and the ascending aorta together, using a special proximal transcatheter aortic valve connected to an uncovered stent-graft portion, called the "endo Bentall" concept. Unquestionably, this is an exceptional procedure, indicated only in highly selected cases, but it shows that even the ascending aorta could be suitable for totally endovascular interventions ${ }^{[53,54]}$.

\section{LEFT ATRIAL APPENDAGE OCCLUSION}

Atrial fibrillation (AF) occurs in more than $10 \%$ of octogenarians, and it is the most common arrhythmia in the TAVI population ${ }^{[55]}$. In the first PARTNER cohorts, chronic AF was present in $32.9 \%$ of inoperable ones $^{[1]}$ and in $40.8 \%$ of high-risk patients who underwent TAVI ${ }^{[2]}$. Compared to sinus rhythm, AF was associated with double 1-year mortality $(26.2 \% \text { vs. } 12.9 \%)^{[56]}$.

Regardless of the type (paroxysmal, persistent, or permanent), AF is a strong predictor of stroke ${ }^{[57]}$, and it is independently associated with late cardiovascular morbidity and mortality after TAVI ${ }^{[58]}$. The explanation for these risks goes beyond its thromboembolic potential; it is also linked to the risk of major bleeding due to oral anticoagulation (AF treatment) plus dual antiaggregation (indicated after TAVI) ${ }^{[59]}$.

Although there is a lack of evidence supporting the best strategy for stroke prevention in TAVI patients with pre-existing AF, the left atrial appendage occlusion (LAAO) strategy, especially in patients with high risk of bleeding, could be an attractive option. The main advantage of combining LAAO with TAVI is to provide a treatment that has proven to prevent stroke with efficacy similar, or even superior, to $\operatorname{warfarin}^{[60,61]}$.

It is important to remember, however, that LAAO mitigates only the risk of embolization of thrombi formed inside the left atrial appendage, having no effect on clots formed in the valve, or on calcium embolization due to TAVI advancement or positioning. To try to cover these other factors, Gafoor et al. ${ }^{[62]}$ suggest that the use of smaller sheaths, better delivery systems, and easier-to-position devices, besides carotid protection systems, may provide more complete stroke prevention during TAVI. 

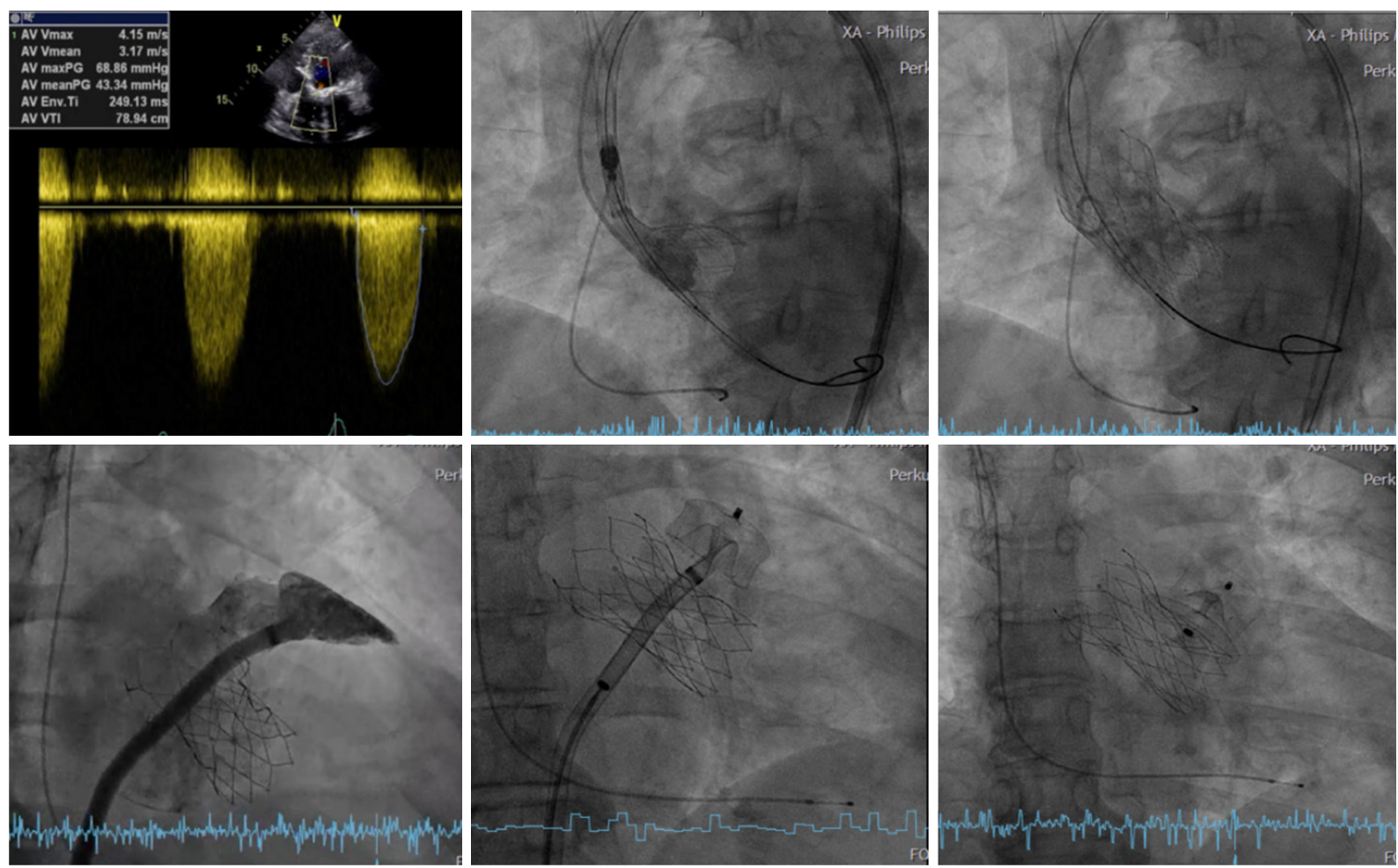

Figure 3. Transcatheter aortic valve implantation simultaneous with left atrial appendage occlusion in a 73-year-old female patient with severe symptomatic aortic stenosis (the first image) and persistent atrial fibrillation. The patient had a previous history of anemia and lower gastrointestinal bleeding associated with anticoagulation use. The procedure was started by a transfemoral implantation of a 27-mm self-expanding Portico valve. After transcatheter aortic valve implantation, the left atrial appendage was angiographically measured, and an left atrial appendage occlusion occluder was implanted (Amplatzer Amulet Occluder 28 mm)

In terms of potential risks, combined procedures require an additional venous access and a transseptal puncture, increasing procedural time and the contrast volume used. Despite this, no impact on periprocedural morbidity and mortality of LAAO combined with TAVI has been observed ${ }^{[55,63]}$.

Based on these data, the best candidates for LAAO concomitant with TAVI seem to be those with chronic $\mathrm{AF}$ and established contraindications to anticoagulation, or those with high risk of bleeding. When a concomitant approach is chosen, usually LAAO is addressed after TAVI [Figure 3].

\section{ATRIAL SEPTAL DEFECT AND PATENT FORAMEN OVALE CLOSURE}

Patent foramen ovale (PFO) and atrial septal defect (ASD) are defects of the interatrial septum. Normally, after birth, the elevation in left atrial pressure forces the septum primum and septum secundum together, collapsing the space between them. In approximately $20 \%$ of the population, however, a PFO persists ${ }^{[64]}$, and it becomes a possible conduit for thrombi, air, or vasoactive peptides.

Percutaneous PFO and ASD closure are feasible and effective in reducing paradoxical embolism and preventing secondary stroke, as demonstrated by the extended follow-up of the RESPECT trial (Randomized Evaluation of Recurrent Stroke Comparing PFO Closure to Established Current Standard of Care Treatment) and the CLOSE trial (PFO Closure or Anticoagulants Versus Antiplatelet Therapy to Prevent Stroke Recurrence). In the former, PFO closure significantly reduced ischemic recurrence when compared to medical therapy, with a number needed to treat (NNT) of 45 ( $\mathrm{HR}=0.55,95 \% \mathrm{CI}: 0.31-0.999 ; \mathrm{NNT} 45)$, while in the CLOSE trial, NNT was only $17(\mathrm{HR}=0.03,95 \% \mathrm{CI}: 0-0.26)^{[65,66]}$. 

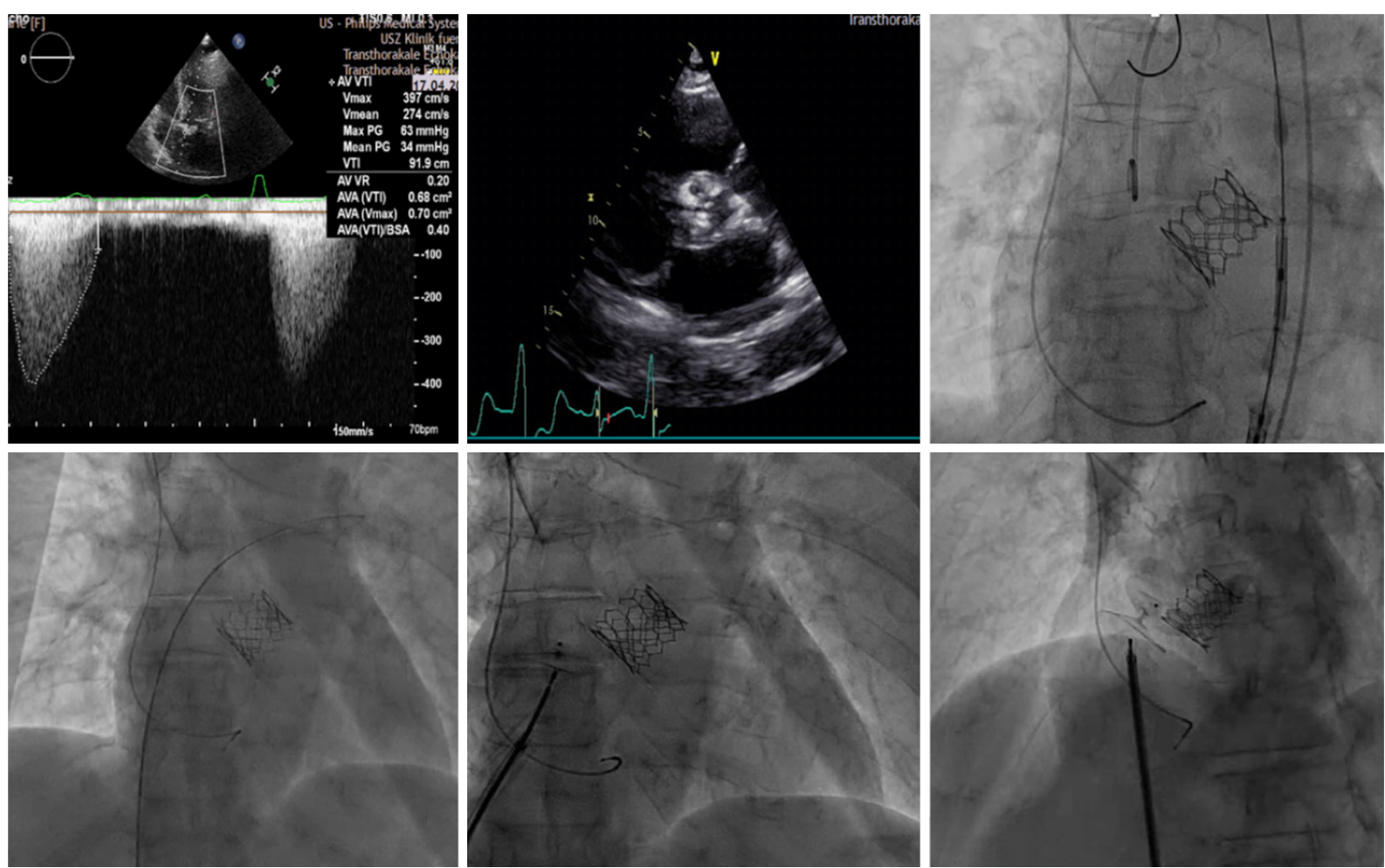

Figure 4. Transcatheter aortic valve implantation concomitant with patent foramen ovale closure in a 70-year-old female patient with severe symptomatic aortic stenosis (the first 2 images) and patent foramen ovale with atrial septal aneurysm. The patient had a previous history of stroke and Heyde syndrome (induced Von Willebrand disease, lower gastrointestinal bleeding, and anemia). A transfemoral 26-mm balloon-expandable Edwards SAPIEN 3 valve was implanted, followed by patent foramen ovale closure using a 30-mm patent foramen ovale occluder

Considering that PFO closure is safe, technically simple, effective, and can be carried out by a single surgeon in less than $15 \mathrm{~min}$, Taramasso et al. ${ }^{[67]}$ believe that this intervention may be justified, especially in the presence of anatomical characteristics such as atrial septal aneurysm, Eustachian valve and Chiari network, or in the presence of a large spontaneous shunt.

In terms of a combined PFO/ASD and TAVI procedure, Pasic et al. ${ }^{[68]}$ reported, in 2011, the first case of TAVI simultaneous with an ASD transcatheter closure. Later, in 2014, Khattab et al. ${ }^{[63]}$ reported the results of 10 TAVI procedures combined with other structural heart interventions. PFO closure was performed using a 25-mm Amplatzer PFO Occluder in two patients, while ASD closure was performed using a 24-mm Amplatzer Septal Occluder in one patient. No residual shunts or thrombi were seen after the procedure. The authors pointed out the feasibility of the combined approach, but also stressed that high-volume centers, with experienced surgeons, are needed to obtain proper results.

When a concomitant approach is performed, the strategy is similar as with LAAO, starting with TAVI [Figure 4].

\section{COST-EFFECTIVENESS ANALYSES}

Despite the fact that a precise definition of the best timing for treating concurrent comorbidities in patients undergoing TAVI remains unknown, a common additional factor to take into account in the decisionmaking process is the local reimbursement policies. Although TAVI procedural costs exceed those of surgical aortic valve replacement, many cost-effectiveness analyses have shown that a shorter length of 


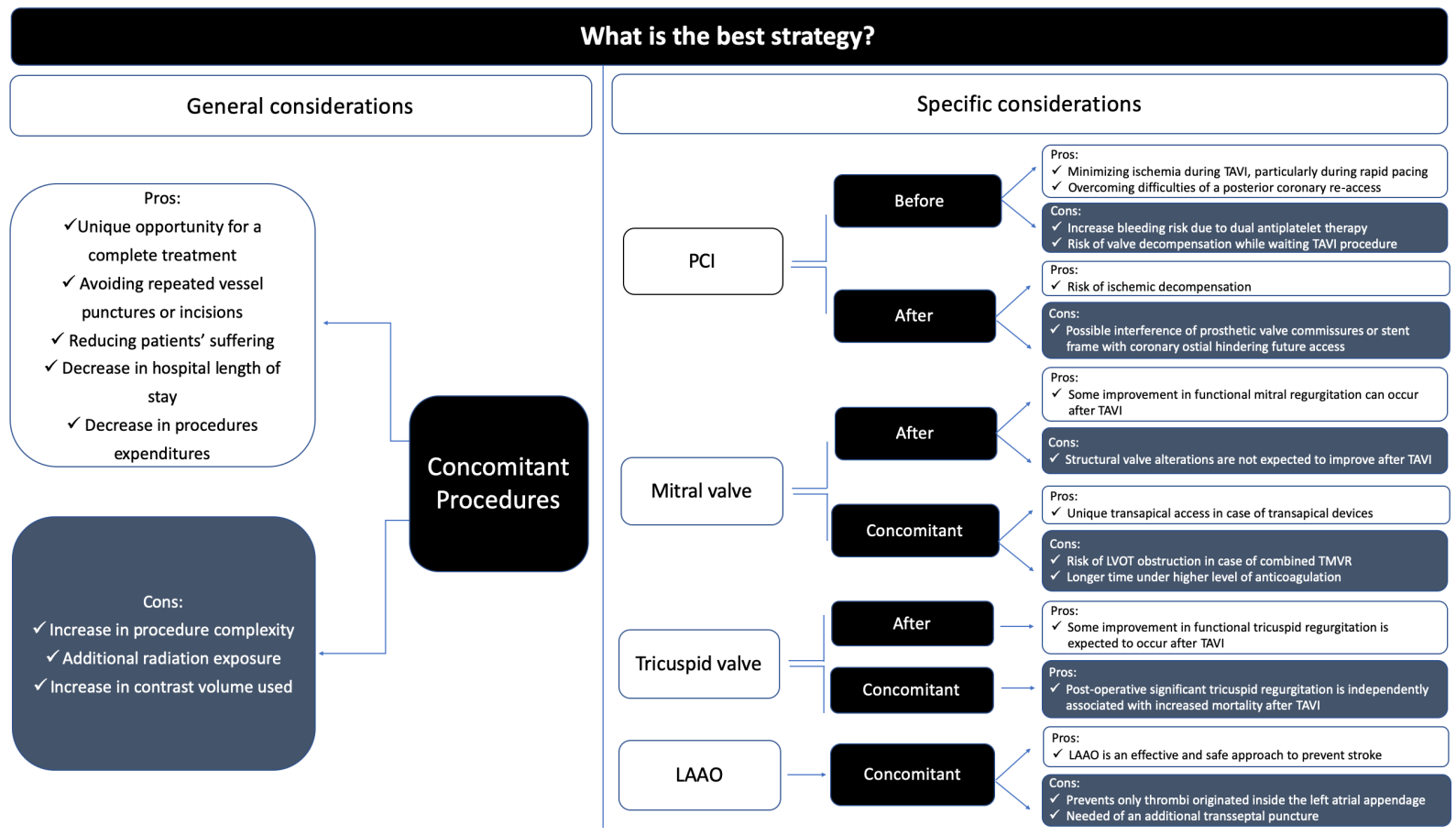

Figure 5. Pros and cons of TAVI combined with other transcatheter interventions. TAVI: transcatheter aortic valve implantation; PCI: percutaneous coronary intervention; LAAO: left atrial appendage occlusion

hospital stay and a reduced need for post-acute rehabilitation services make TAVI a cost-effective approach, particularly when transfemoral access is suitable. In the setting of concomitant functional MR and AS, a cost-effective approach would be to perform TAVI first, followed by the mitral intervention in those who do not experience improvement in MR, reducing, therefore, the number of mitral valve interventions in comparison to routine simultaneous procedures ${ }^{[28]}$. On the other hand, concomitant PCI and TAVI have the potential to reduce operational and re-hospitalization costs, and has been considered ${ }^{[69]}$. Regarding the other possible combinations, many health insurance companies have the policy of not paying for a combined intervention, which may have an impact on final reimbursement value and somehow discourage concomitant approaches ${ }^{[70]}$.

\section{CONCLUSION}

In this paper, we present an update on the most frequent indications for TAVI combined with other transcatheter procedures, whose pros and cons are summarized in Figure 5.

In patients with concomitant heart disease, such as $\mathrm{CAD}$, mitral or tricuspid valve disease, atrial fibrillation, PFO or ASD, or aorta aneurysm, especially in those not candidates for complex conventional surgery, TAVI combined with other transcatheter interventions offers a unique opportunity for a complete treatment, either by staged or simultaneous interventions.

The decision about which approach (staged $v s$. single session) is more suitable for each patient needs to be based on individual characteristics and clinical, anatomical, and procedure-related factors.

\section{DECLARATIONS}

\section{Authors' contributions}

Made substantial contributions to the conception, design and review of this article: Tagliari AP, Taramasso $\mathrm{M}$ 


\section{Availability of data and materials}

Not applicable.

\section{Financial support and sponsorship}

Dr. Tagliari’s scientific research is supported by Coordenação de Aperfeiçoamento de Pessoal de Nível Superior - Brasil (Capes) - Finance Code 001.

\section{Conflicts of interest}

Dr. Taramasso is a consultant for Abbott Vascular, Boston Scientific, 4TECH, and CoreMedic; and has received speaker honoraria from Edwards Lifesciences.

\section{Ethical approval and consent to participate}

Not applicable.

\section{Consent for publication}

Not applicable.

\section{Copyright}

(c) The Author(s) 2020.

\section{REFERENCES}

1. Leon MB, Smith CR, Mack MJ, Miller DC, Moses JW, et al. Transcatheter aortic-valve implantation in patients who cannot undergo surgery. N Engl J Med 2010;363:1597-607.

2. Smith CR, Leon MB, Mack MJ, Miller DC, Moses JW, et al. Transcatheter versus surgical aortic-valve replacement in high-risk patients. N Engl J Med 2011;364:2187-98.

3. Gilard M, Eltchaninoff H, Iung B, Donzeau-Gouge P, Chevreul K, et al. Registry of transcatheter aortic-valve implantation in high-risk patients. N Engl J Med 2012;366:1705-15.

4. Paradis JM, Fried J, Nazif T, Kirtane A, Harjai K, et al. Aortic stenosis and coronary artery disease: what do we know? What don't we know? A comprehensive review of the literature with proposed treatment algorithms. Eur Heart J 2014;35:2069-82.

5. Adams DH, Popma JJ, Reardon MJ, Yakubov SJ, Coselli JS, et al. Transcatheter aortic-valve replacement with a self-expanding prosthesis. N Engl J Med 2014;370:1790-8.

6. Leon MB, Smith CR, Mack MJ, Makkar RR, Svensson LG, et al. Transcatheter or surgical aortic-valve replacement in intermediate-risk patients. N Engl J Med 2016;374:1609-20.

7. Reardon MJ, Van Mieghem NM, Popma JJ, Kleiman NS, Søndergaard L, et al. Surgical or transcatheter aortic-valve replacement in intermediate risk patients. N Engl J Med 2017;376:1321-31.

8. Mack MJ, Leon MB, Thourani VH, Makkar R, Kodali SK, et al. Transcatheter aortic-valve replacement with a balloon-expandable valve in low-risk patients. N Engl J Med 2019;380:1695-705.

9. Popma JJ, Deeb GM, Yakubov SJ, Mumtaz M, Gada H, et al. Transcatheter aortic-valve replacement with a self-expanding valve in lowrisk patients. N Engl J Med 2019;380:1706-15.

10. Baumgartner H, Falk V, Bax JJ, De Bonis M, Hamm C, et al. ESC/EACTS Guidelines for the management of valvular heart disease: the task force for the management of valvular heart disease of the European Society of Cardiology (ESC) and the European Association for Cardio-Thoracic Surgery (EACTS). Eur Heart J 2017;38:2739-91.

11. Yang Y, Huang FY, Huang BT, Xiong TY, Pu XB, et al. The safety of concomitant transcatheter aortic valve replacement and percutaneous coronary intervention: a systematic review and meta-analysis. Medicine (Baltimore) 2017;96:e8919.

12. Penkalla A, Pasic M, Drews T, Buz S, Dreysse S, et al. Transcatheter aortic valve implantation combined with elective coronary artery stenting: a simultaneous approach. Eur J Cardiothorac Surg 2015;47:1083-9.

13. Li J, Patel SM, Nadeem F, Thakker P, Al-Kindi S, et al. Impact of residual coronary atherosclerosis on transfemoral transcatheter aortic valve replacement. Catheter Cardiovasc Interv 2019;93:545-52.

14. Blumenstein J, Kim W, Liebetrau C, Gaede L, Kempfert J, et al. Challenges of coronary angiography and intervention in patients previously treated by TAVI. Clin Res Cardiol 2015;104:632-9.

15. Tang GHL, Zaid S, Gupta E, Ahmad H, Patel N, et al. Impact of initial evolut transcatheter aortic valve replacement deployment orientation on final valve orientation and coronary reaccess. Circ Cardiovasc Interv 2019;12:e008044.

16. Ochiai T, Yoon SH, Flint N, Sharma R, Patel V, et al. TCT-683 variation in the timing of percutaneous coronary intervention and outcomes in patients undergoing transcatheter aortic valve replacement. J Am Coll Cardiol 2019;74:B670.

17. Hutter A, Bleiziffer S, Richter V, Opitz A, Hettich I, et al. Transcatheter aortic valve implantation in patients with concomitant mitral and 
tricuspid regurgitation. Ann Thorac Surg 2013;95:77-84.

18. Webb JG, Pasupati S, Humphries K, Thompson C, Altwegg L, et al. Percutaneous transarterial aortic valve replacement in selected highrisk patients with aortic stenosis. Circulation 2007;116:755-63.

19. Tzikas A, Piazza N, van Dalen BM, Schultz C, Geleijnse ML, et al. Changes in mitral regurgitation after transcatheter aortic valve implantation. Catheter Cardiovasc Interv 2010;75:43-9.

20. Barbanti M, Webb JG, Hahn RT, Feldman T, Boone RH, et al. Impact of preoperative moderate/severe mitral regurgitation on 2-year outcome after transcatheter and surgical aortic valve replacement: insight from the Placement of Aortic Transcatheter Valve (PARTNER) Trial Cohort A. Circulation 2013;128:2776-84.

21. Toggweiler S, Boone RH, Rodes-Cabau J, Humphries KH, Lee M, et al. Transcatheter aortic valve replacement: outcomes of patients with moderate or severe mitral regurgitation. J Am Coll Cardiol 2012;59:2068-74.

22. Nombela-Franco L, Eltchaninoff H, Zahn R, Testa L, Leon MB, et al. Clinical impact and evolution of mitral regurgitation following transcatheter aortic valve replacement: a meta-analysis. Heart 2015;101:1395-405.

23. Bedogni F, Latib A, DeMarco F, Agnifili M, Oreglia J, et al. Interplay between mitral regurgitation and transcatheter aortic valve replacement with the CoreValve Revalving System: a multicenter registry. Circulation 2013;128:2145-53.

24. Cortes C, Amat-Santos IJ, Nombela-Franco L, Munoz-Garcia AJ, Gutierrez-Ibanes E, et al. Mitral regurgitation after transcatheter aortic valve replacement: prognosis, imaging predictors, and potential management. J Am Coll Cardiol Cardiovasc Interv 2016;9:1603-14.

25. Taramasso M, Maisano F, Nietlispach F. TAVI and concomitant procedures: from PCI to LAA closure. EuroIntervention 2015;11:W96-100.

26. Ruel M, Kapila V, Price J, Kulik A, Burwash IG, et al. Natural history and predictors of outcome in patients with concomitant functional mitral regurgitation at the time of aortic valve replacement. Circulation 2006;114:I541-6.

27. Almasood A, Al Ahmari S, El-Shurafa H, Alotaibi M, Al Kasab S, et al. The change in mitral regurgitation severity after transcatheter aortic valve implantation. J Saudi Heart Assoc 2015;27:10-7.

28. Stähli BE, Reinthaler M, Leistner DM, Landmesser U, Lauten A. Transcatheter aortic valve replacement and concomitant mitral regurgitation. Front Cardiovasc Med 2018;5:74.

29. Ando T, Takagi H, Briasoulis A, Telila T, Slovut DP, et al. A systematic review of reported cases of combined transcatheter aortic and mitral valve interventions. Catheter Cardiovasc Interv 2018;91:124-34.

30. Veronesi F, Corsi C, Sugeng L, Mor-Avi V, Caiani EG, et al. A study of functional anatomy of aortic-mitral valve coupling using 3D matrix transesophageal echocardiography. Circ Cardiovasc Imaging 2009;2:24-31.

31. Stelzmueller ME, Zilberszac R, Heinrich N, Mora B, Laufer G, et al. Concomitant transapical transcatheter aortic valve implantation and transapical mitral valve repair with neochord implantation. Innovations (Phila) 2019;14:564-8.

32. Guerrero M, Dvir D, Himbert D, Urena M, Eleid M, et al. Transcatheter mitral valve replacement in native mitral valve disease with severe mitral annular calcification: Results from the first multicenter global registry. J Am Coll Cardiol Intv 2016;9:1361-71.

33. Fanari Z, Mahmaljy H, Nandish S, Goswami NJ. Simultaneous transcatheter transfemoral aortic and transseptal mitral valve replacement using Edward SAPIEN S3. Catheter Cardiovasc Interv 2018;92:988-92.

34. Sannino A, Grayburn PA. Mitral regurgitation in patients with severe aortic stenosis: diagnosis and management. Heart 2018;104:16-22.

35. Katte F, Franz M, Jung C, Figulla HR, Leistner D, et al. Impact of concomitant mitral regurgitation on transvalvular gradient and flow in severe aortic stenosis: a systematic ex vivo analysis of a subentity of low-flow low-gradient aortic stenosis. EuroIntervention 2018;13:1635-44.

36. Bruce CJ, Connolly HM. Right-sided valve disease deserves a little more respect. Circulation 2009;119:2726-34.

37. Kim HK, Kim YJ, Park JS, Kim KH, Kim KB, et al. Determinants of the severity of functional tricuspid regurgitation. Am J Cardiol 2006;98:236-42.

38. Wilbring M, Tugtekin SM, Ritzmann M, Arzt S, Schmidt T, et al. Transcatheter aortic valve implantation reduces grade of concomitant mitral and tricuspid valve regurgitation and pulmonary hypertension. Eur J Cardiothorac Surg 2014;46:818-24.

39. Lindman BR, Maniar HS, Jaber WA, Lerakis S, Mack MJ, et al. Effect of tricuspid regurgitation and the right hear on survival after transcatheter aortic valve replacement: insights from the Placement of Aortic Transcatheter Valves II inoperable cohort. Circ Cardiovasc Interv 2015;8:pii: e002073.

40. Takagi H, Hari Y, Kawai N, Ando T; ALICE (All-Literature Investigation of Cardiovascular Evidence) Group. Impact of concurrent tricuspid regurgitation on mortality after transcatheter aortic-valve implantation. Catheter Cardiovasc Interv 2019;93:946-53.

41. Pavasini R, Ruggerini S, Grapsa J, Biscaglia S, Tumscitz C, et al. Role of the tricuspid regurgitation after mitraclip and transcatheter aortic valve implantation: a systematic review and meta-analysis. Eur Heart J Cardiovasc Imaging 2018;19:654-9.

42. Barbanti M, Binder RK, Dvir D, Tan J, Freeman M, et al. Prevalence and impact of preoperative moderate/severe tricuspid regurgitation on patients undergoing transcatheter aortic valve replacement. Cathet Cardiovasc Intervent 2015;85:677-84.

43. Reichart D, Schofer N, Deuschl F, Schaefer A, Blankenberg S, et al. Transcatheter tricuspid valve-in-ring and aortic valve-in-valve implantation. Thorac Cardiovasc Surg Rep 2017;6:e29-31.

44. Sideris S, Drakopoulou M, Oikonomopoulos G, Gatzoulis K, Stavropoulos G, et al. Left ventricular pacing through coronary sinus is feasible and safe for patients with prior tricuspid valve intervention. Pacing Clin Electrophysiol 2016;39:378-81.

45. Faurie B, Abdellaoui M, Wautot F, Staat P, Champagnac D, et al. Rapid pacing using the left ventricular guidewire: reviving an old technique to simplify BAV and TAVI procedures. Catheter Cardiovasc Interv 2016;88:988-93.

46. Abdi S, Nazeri I, Mandegar MH, Geraiely B, Mortazavi SH. Single-session double valve replacement: TAVI + tricuspid valve-in-valve procedures. J Card Surg 2019;34:518-21.

47. Kurra V, Schoenhagen P, Roselli EE, Kapadia SR, Tuzcu EM, et al. Prevalence of significant peripheral artery disease in patients 
evaluated for percutaneous aortic valve insertion: preprocedural assessment with multidetector computed tomography. J Thorac Cardiovasc Surg 2009;137:1258-64.

48. Perlman GY, Loncar S, Pollak A, Gilon D, Alcalai R, et al. Post-procedural hypertension following transcatheter aortic valve implantation: incidence and clinical significance. JACC Cardiovasc Interv 2013;6:472-8.

49. Sato Y, Horiuchi Y, Yahagi K, Okuno T, Kusuhara T, et al. Simultaneous transcatheter aortic valve implantation and endovascular aneurysm repair in a patient with very severe aortic stenosis with abdominal aortic aneurysm. J Cardiol Cases 2018;17:123-5.

50. Mauri S, Bozzani A, Ferlini M, Aiello M, Gazzoli F, et al. Combined transcatheter treatment of severe aortic valve stenosis and infrarenal abdominal aortic aneurysm in increased surgical risk patients. Ann Vasc Surg 2019;60:480.e1-e5.

51. Natour M, Rabin A, Avraham E, Dannenberg C, Ronen Jaffe R, et al. Combined urgent transcatheter aortic valve implantation and endovascular aneurysm repair for symptomatic abdominal aortic aneurysm. J Vasc Surg 2018;68:e140.

52. Komlo CM, Vallabhajosyula P, Bavaria JE, Desai ND, Anwaruddin S, et al. Combined transaortic transcatheter valve replacement and thoracic endografting. Ann Thorac Surg 2014;97:696-8.

53. Rylski B, Szeto WY, Bavaria JE, Branchetti E, Moser W, et al. Development of a single endovascular device for aortic valve replacement and ascending aortic repair. J Card Surg 2014;29:371-6.

54. Saadi EK, Tagliari AP, Almeida RMS. Endovascular treatment of the ascending aorta: is this the last frontier in aortic surgery? Braz J Cardiovasc Surg 2020;34:759-64.

55. Attinger-Toller A, Maisano F, Senn O, Taramasso M, Shakir S, et al. "One-stop shop": safety of combining transcatheter aortic valve replacement and left atrial appendage occlusion. JACC Cardiovasc Interv 2016;9:1487-95.

56. Biviano AB, Nazif T, Dizon J, Garan H, Fleitman J, et al. Atrial fibrillation is associated with increased mortality in patients undergoing transcatheter aortic valve replacement: insights from the placement of aortic transcatheter valve (PARTNER) trial. Circ Cardiovasc Interv 2016;9:e02766.

57. Nombela-Franco L, Webb JG, de Jaegere PP, Toggweiler S, Nuis RJ, et al. Timing, predictive factors, and prognostic value of cerebrovascular events in a large cohort of patients undergoing transcatheter aortic valve implantation. Circulation 2012;126:3041-53.

58. Yankelson L, Steinvil A, Gershovitz L, Leshem-Rubinow E, Furer A, et al. Atrial fibrillation, stroke, and mortality rates after transcatheter aortic valve implantation. Am J Cardiol 2014;114:1861-6.

59. Stepinska J, Czerwinska K, Witkowski A, Dąbrowski M, Chmielak Z, et al. Risk factors for bleeding complications in patients undergoing transcatheter aortic valve implantation (TAVI). Cardiol J 2013;20:125-33.

60. Holmes DR, Reddy VY, Turi ZG, Doshi SK, Sievert H, et al. Percutaneous closure of the left atrial appendage versus warfarin therapy for prevention of stroke in patients with atrial fibrillation: a randomised non-inferiority trial. Lancet 2009;374:534-42.

61. Reddy VY, Möbius-Winkler S, Miller MA, Neuzil P, Schuler G,et al. Left atrial appendage closure with the Watchman Device in patients with a contraindication for oral anticoagulation: the ASAP Study (ASA Plavix Feasibility Study With Watchman Left Atrial Appendage Closure Technology). J Am Coll Cardiol 2013;61:2551-6.

62. Gafoor S, Heuer L, Franke J, Bertog S, Vaskelyte L, et al. Transcatheter aortic valve replacement and left atrial appendage occlusion - a stitch in time? Interv Cardiol 2014;9:126-9.

63. Khattab AA, Gloekler S, Sprecher B, Shakir S, Guerios E, et al. Feasibility and outcomes of combined transcatheter aortic valve replacement with other structural heart interventions in a single session: a matched cohort study. Open Heart 2014;1:e000014.

64. Handke M, Harloff A, Olschewski M, Hetzel A, Geibel A. Patent foramen ovale and cryptogenic stroke in older patients. N Engl J Med 2007;357:2262-8.

65. Saver JL, Carroll JD, Thaler DE, Smalling RW, MacDonald LA, et al. Long-term outcomes of patent foramen ovale closure or medical therapy after stroke. N Engl J Med 2017;377:1022-32.

66. Mas JL, Derumeaux G, Guillon B, Massardier E, Hosseini H, et al. Patent foramen ovale closure or anticoagulation vs. antiplatelets after stroke. N Engl J Med 2017;377:1011-21.

67. Taramasso M, Nietlispach F, Maisano F, Meier B. Patent foramen ovale: indications for closure and techniques. EuroIntervention 2016;12:X7-12.

68. Pasic M, Berger F, D'Ancona G, Dreysse S, Buz S, et al. Transcatheter aortic valve implantation and simultaneous closure of ostium secundum atrial septal defect. Heart Surg Forum 2011;14:E354-6.

69. Bao L, Gao Q, Chen S, Chen Y, Elhmidi Y, et al. Feasibility and safety of combined percutaneous coronary intervention among highrisk patients with severe aortic stenosis undergoing transcatheter aortic valve implantation: a systematic review and meta-analysis. Eur J Cardiothorac Surg 2018;54:1052-9.

70. Gilhofer TS, Obeid S, Luescher TF, Binder RK. Simultaneous transcatheter aortic valve implantation and left atrial appendage occlusion versus both interventions as stand-alone procedures. Structural Heart 2018;2:492-7. 